\title{
The politics of citizenship and difference in Sri Lankan schools
}

Sørensen, Birgitte

Published in:

Anthropology \& Education Quarterly

DOI:

10.1111/j.1548-1492.2008.00031.x

Publication date:

2008

Document version

Publisher's PDF, also known as Version of record

Citation for published version (APA):

Sørensen, B. (2008). The politics of citizenship and difference in Sri Lankan schools. Anthropology \& Education Quarterly, 39(4), 423-443. https://doi.org/10.1111/j.1548-1492.2008.00031.x 


\title{
The Politics of Citizenship and Difference in Sri Lankan Schools
}

\author{
BIRGITTE REFSLUND SøRENSEN \\ University of Copenhagen
}

This article explores the formation of citizenship in Tamil-medium minority schools in Sri Lanka. It is argued that although the new curriculum aims to construct an inclusive notion of national citizenship, the influence of politics on education in reality creates dominant experiences of discrimination and marginalization. I argue, however, that in the more resourceful communities, social networks are effectively put to work to generate an alternative authoritative notion of peripheral citizenship. [citizenship, minorities, education, Sri Lanka]

Sri Lanka has for the past three decades been undergoing fast and profound economic, political, social, and cultural transformations caused by globalization and violent conflicts between the government and various political groups. These processes affect the constitution of Sri Lanka as state, nation, and society with implications for how different population groups can imagine and identify themselves and others, and for the rights and duties of different groups. The formation of citizens in response to new challenges and opportunities takes place in many institutional and social settings. Sri Lanka has made huge investments in the construction of schools and training of teachers to make education available and accessible to all children regardless of socioeconomic background and region of residence.

Today the net enrollment in primary education is close to 100 percent, and children spend many hours every day in school, attending private tuition classes, and doing homework. This makes the school a fundamental institutional site for the ongoing cultural formation and disciplining of children as citizens.

There are several questions regarding education in Sri Lanka: What kinds of citizens are created in the schools? What kinds of skills and knowledge are learned? What kind of social and moral values are taught? What views of diversity and difference are produced in the schools today? This article explores what kinds of citizens the Sri Lankan nation-state has attempted to create through education and how schoolchildren belonging to Sri Lanka's two largest minorities, the Tamils and the Muslims, construct their citizenship in the school environment, where they are concurrently exposed to the often contradictory official discourses of textbooks and the social memories and interests of their communities. Underlying this inquiry is a concern about whether education in Sri Lanka is a positive and constructive force contributing to social development and peace, or whether it is a largely negative and destructive force that fosters growing inequality and social conflicts (Bush and Saltarelli 2000; Davis 2006; Smith and Vaux 2003).

My use of the terms citizen and citizenship is inspired by recent anthropological explorations of the subject, which share a critique of state-centered, legal definitions of citizenship as the basis for social analysis. In political science, citizenship is commonly treated as a relationship between the state and the individual, and emphasis is on the

Anthropology \& Education Quarterly, Vol. 39, Issue 4, pp.423-443, ISSN 0161-7761, online ISSN 1548-1492. (C) 2008 by the American Anthropological Association. All rights reserved.

DOI:10.1111/j.1548-1492.2008.00031.x. 
individual's political and civil rights as a member of a nation-state. The anthropological perspective instead considers citizenship a notion or idea that is ascribed different meanings and significance in particular historical, cultural, social, and political contexts, and that is evolving in response to changing worlds (Jeffery 2005; Kabeer 2005; Stewick and Levinson 2007). The anthropological perspective often also assigns particular importance to its construction from below, captured in concepts such as "cultural citizenship" (Rosaldo 1994), "societal citizenship" (Kabeer 2005), and "folk paradigms of justice" (Fraser 2003).

The advantage of this approach is that it connects an abstract concept to people's concrete experiences, concerns, and aspirations as they emerge. They are given meaning and expressed within particular social worlds. However, for it to remain useful as an analytical term it is necessary to define its core content that crosscuts the many localized versions. On the basis of ethnographic research in different parts of the world, Kabeer (2005) identifies certain values that all people associate with citizenship, and she suggests that these may therefore serve as a way of delineating the concept. One value is "justice," which focuses on when it is considered fair to treat people equally and when decisions should be based on differences. The second value is "recognition," which addresses both the intrinsic worth of all human beings and the respect for their differences. The third value is "self-determination," which deals with people's ability to exercise some degree of control over their own lives. Finally there is "solidarity," which considers the capacity to identify with others and to act in unity with them in their claims for justice and recognition. Kabeer suggests that the four dimensions of citizenship are often interrelated in people's lives, but she does not elaborate further on this.

Departing from a similar preoccupation, Fraser (2003) argues that virtually every experience of subordination and injustice contains elements of both redistribution and recognition, which should be united in a single theoretical framework that stresses their interrelationship and interpenetration. Thus, she proposes a "perspectival dualism" in which the two categories exist as cofundamental and mutually irreducible aspects of justice (Fraser 2003:3). Fraser's perspectival dualism can help us better comprehend how education generates complex experiences of justice and injustice and enhance our understanding of how notions of citizenship emerge and develop within the educational field.

Ong (1996) likewise advocates for an anthropological approach to citizenship that recognizes the concept's social embeddedness. According to Ong this implies that definitions of citizenship inevitably take place within asymmetrical relations of power and are objects of continual contestation. With inspiration from Foucault, Ong defines citizenship as "a cultural process of 'subject-ification,' or subject-making, which entails the dual dimensions of 'self-making' and 'being-made' " (1996:737). Constructions of citizens, in other words, are never the direct result of nation-state projects or of the subjects' own efforts, but are mediated outcomes. In continuation of her problematization of unidimensional analyses that tend to exaggerate the agency and control of either state or subject, Ong suggests that attention be paid to the role of civil institutions and social groups as part of a wider governance structure (1996:738). The social setting for the formation of citizenship in Ong's view is not simply a context, nor is it just a container of localized meanings of citizenship. The social setting is a complex constellation of actors with vested interests and uneven access to power that engage actively and vehemently in the production of citizens. The above theoretical 
conceptualizations of citizenship constitute my starting point for exploring what kinds of citizens are created within Sri Lankan schools today.

The article is divided into three parts. The first part discusses the development of Sri Lanka's education policies and priorities from a historical perspective and shows that although Sri Lanka has been effective in building up a mass-education system that provides every child with basic literacy and numeracy skills, education has not resulted in a more even distribution of resources and hope, nor has it succeeded in uniting children of different backgrounds and identities under the umbrella of an inclusive national identity. Instead education has become a contentious issue that mobilizes many in search of better futures and in political and even violent struggles for justice. The section concludes with a discussion of the most recent educational reforms, which attempt to address this particular challenge of growing social disparity and disruptive violence by giving increased attention to citizenship education.

The second part of the article builds on ethnographic research with schoolchildren and teachers in minority schools in Northwestern Sri Lanka. In this section I explore how schoolchildren are continuously being-made and are self-making through their engagement with teachers and authorities, the consumption of official textbooks, and through a reading of their school's relative standard and a commitment to the community's social memory. As I show in the following section, community members do not passively accept when their schools receive insufficient resources and support, but mobilize available social networks to improve the availability and quality of education and through this their position as citizens.

\section{Education Policy and Sinhalese Nation-Building}

Sri Lanka's transition from colony to independent nation-state in 1948 was remarkably peaceful. ${ }^{1}$ In less than a decade, however, the unity and harmony was broken and replaced by political struggles that eventually escalated into violent conflicts on several fronts from the 1970s. What is little recognized is that shifting education policies played a decisive role in establishing this antagonistic environment. In 1944 the British government established a commission to consider necessary constitutional reforms in Sri Lanka, and in its final report it emphasized that the relationship between the Sinhalese majority and the different minority groups posed a serious challenge. The constitution of 1945 safeguarded the basic rights of linguistic, religious minorities, but in 1956 the newly elected nationalist government adopted a new language act that made Sinhala, the language of the Sinhalese majority the only official language of the country. At the same time a process of government takeover of schools was initiated, which served to reduce the influence of missionary schools, nationalize the school system, and to make education available to all children (Little 2003b:92-94; Nissan 1996:34-37).

The last goal emerged in response to growing pressure from Sinhalese voters to improve opportunities for the Sinhalese youths, who were dissatisfied that the Tamil minority dominated the public sectors because of privileged access to education under colonial rule. To achieve mass education English was replaced with swabasha, the vernacular languages, as the medium of instruction. The switch to teaching in the vernacular was perceived to facilitate learning for all children and moreover, it signaled a political break with the colonial heritage. However, the policy had damaging repercussions for interethnic relations and contributed to a segregation of education 
on ethnic and linguistic grounds, a division that still prevails. Although children of a Sinhalese background generally benefited from the government's policy, the policy had long-term negative consequences for Tamil-speaking children, as their access to public-sector jobs was restricted, because proficiency in the Sinhalese language was now required as a result of the Sinhala Only Act.

The Tamils experienced further marginalization a decade later, when new policies for university admissions were approved. All students had previously participated in the same competitive examinations to gain entrance to the university, but from 1971 access to university became regulated on the basis of language and this meant that Tamil-speaking students required higher marks. A year later, a district quota system was adopted to compensate for the fact that children in the rural areas did not have access to the same quality education as children in the urban areas. The end result was a dramatic decrease in the number of places for Tamils at universities. In some disciplines, especially science-based disciplines, the Tamils' admittance dropped by up to two-thirds, whereas the number of Sinhalese students increased significantly (Matthews 1995:80; Nissan 1996:13; Ponnambalam 1983:176-177). Together these alterations of education policy constituted a major blow to the status and future prospects of the Tamil population, and experiences of discrimination in education were highly contributory to their growing self-consciousness as an ethnic group and a minority, and became increasingly entrenched in their fight for self-determination. According to Perera, in one study a Tamil informant even claims that "discriminatory education policies were the single most important reason which led them to guerrilla activities" (Nissan 1996:12).

If we return to primary education there are still many unresolved and controversial issues. Tamil advocates direct strong accusations against the government of unequal distribution of financial and human resources, which results in poorly equipped and understaffed Tamil medium schools. They also question the noticeable underrepresentation of Tamils in institutions responsible for policy making, curriculum preparation and textbook production, and the political appointments of principals. Finally, Tamil-medium teaching material is criticized for its poor quality and strong Sinhalese cultural bias. I return to these issues in the second part of this article.

Education remains the official responsibility of the Sri Lankan state, also in the Liberation Tigers of Tamil Eelam (LTTE)-controlled areas. ${ }^{2}$ However, the LTTE has slowly built up its own parallel state institutions-including a LTTE Department of Education that provides special education to children in the areas under its control (LTTE 2006; Stokke 2006). The education provided by the LTTE directly challenges the authority of the Sri Lankan state to define the Tamil nation and the Tamil person, by offering an alternative social imaginary. The foreword of a history textbook issued by the LTTE explains:

The history textbooks by the Sri Lankan government that are taught in the schools are not based on true history, but have exaggerated the Sinhalese community, concealed the greatness of the Tamils and has been twisted in a manner to demean the Tamils.... By teaching Tamil translations of Sinhala works, written by and for the Sinhalese, the Tamil students are taught Sinhalese history, which says that this Sinhala-Buddhist country is only for them and that their history is the history of Eelam. [Sambandan 2004]

Subsequent chapters account for the historic development of Tamil Eelam, the Tamil national anthem, and their red flag with the roaring Tiger, and aim to give the Tamil 
children pride in their cultural identity and make them sympathetic to the struggle. Awareness of a shared cultural heritage is also created through special cultural and language programs. In its fight for self-determination, the LTTE can be seen as proposing and practicing "cultural citizenship" as an alternative to the government's idea of national citizenship (Rosaldo 1994).

Somewhat surprising perhaps, the education policies of the 1950s to the 1970s were also contributory to the political mobilization of Sinhalese youths. As argued above, a growing number of Sinhalese youths in the rural areas had benefited from the education reforms and many had even made it into university (Gunaratna 1990). Having invested their hopes in education, they were now looking forward to receiving their rewards in the form of employment and social mobility. However, these benefits failed to materialize for most. Instead, they witnessed how privileges continued to be bestowed on a small, mainly urban and Westernized elite, whereas the majority of the rural youths were still trapped in an intensifying rural poverty or struggling along in urban centers where they lived under miserable circumstances searching for a better life that seemed increasingly unreachable (Gunaratna 1990:65).

Inspired by socialist class struggles elsewhere in the world, the socialist People's Liberation Front (Janatha Vimukhti Peramuna, or JVP) was founded in 1965 with the aim of staging a socialist revolution. JVP regarded the universities and other institutions of learning as prime sites for the reproduction of abusive neocolonial power relations, and they became a significant venue for the enactment of their political protests and recruitment of cadres who were taken to special education camps for political resocialization.

Describing the situation at one university in the late 1980s, Bruce Matthews writes "Mass rallies and show trials, public humiliations, and even floggings and executions were standard features of what remained of university life" (1995:82). The JVP was behind a countrywide ferocious insurrection to overthrow the government and combat capitalism and international interference in 1971 and in the late 1980s, but was eventually defeated. Today the JVP is part of mainstream politics, but they continue to have many supporters among Sinhalese university students, who are still involved in violent ragging and political mobilization. Most recently, JVP-led university students condemned the government for abandoning the deep-rooted principle of free education at all levels and surrendering to global capitalist forces (The Island 28.02.08). The universities, in other words, remain politicized spaces where fierce competition for power and social recognition along class and ethnic lines takes place, which has turned the educated person into a highly ambiguous figure.

The Muslim population constitutes the second largest minority in Sri Lanka. Historically the Muslims have lived dispersed throughout the country, where they have developed tight economic relationships with neighboring Sinhalese and Tamil communities. The Muslims' political leaders have mostly been drawn from the urban economic elite and have sought to obtain influence and access to resources by supporting the Sinhalese-dominated government, rather than claiming an independent political identity. Yet, as O'Sullivan shows, the economic policies and the growing ethnification of politics from the 1970s resulted in the emergence of a separate Muslim ethnic and political identity, which culminated in the formation of the Sri Lankan Muslim Congress (1999).

According to O'Sullivan, education was involved in this development in more ways. The liberalization of the economy exposed the Muslims to growing competition, as 
other groups, especially the Sinhalese, took up business and trade as a livelihood strategy. As Muslims were generally lacking behind in education, this was soon identified as a crucial area for improvement if the Muslim minority should succeed in protecting its interests. As O'Sullivan puts it, "Muslim businessmen began to consider education as an important element of success both in terms of unlocking new opportunities and maintaining competitiveness with the enlarged number of business rivals" (1999:257).

As the Sinhalese government sought to marginalize the Tamil minority, and furthermore benefited from Muslim political support, the Muslim elite managed to make the government give certain concessions. Muslim training colleges and a new category of Muslim government schools were established, and subjects related to Islam developed (O'Sullivan 1999:255). Next, the university admission rules discussed above also benefited the Muslims, whose access to university education went significantly up and enabled them to enter the competition for attractive public sector jobs (O'Sullivan 1999:257, 261). As education became increasingly vital for the socioeconomic status and mobility of the Muslim minority, it also became a vital political issue. Contrary to the Tamils who emphasized aspects of recognition and selfdetermination over redistribution, the Muslims stressed redistribution and were less adamant on issues regarding recognition and identity.

Sri Lanka's protracted political conflicts have multiple causes and what is considered the most contentious and critical concern shifts over time. Yet as I have shown education is enmeshed in complex ways in all of the country's most consequential conflicts (Perera 2006; Selvarajah 2003). The debates and struggles about education are tied to issues of social justice, recognition, self-determination, and solidarity, Kabeer's (2005) four core elements of citizenship, and Jeffery's assertion that in India "contemporary debates about education reflect struggles over the normative domains of citizenship and identity" also appears applicable to neighboring Sri Lanka (2005:23). As the discussion shows, questions of access to primary and higher education and medium of instruction, are not neutral policy measures to achieve a higher national level of learning, but are instrumental in defining children's and youths' particular place in society, in terms of their identity, social status, and rights. In postcolonial Sri Lanka, it has been the Sinhalese population that has benefited the most from education policies, as their language and religion (Buddhism) were naturalized as the country's official and as their access to better employment and income improved considerably. Therefore, the government's policies have been bitterly contested and criticized for not recognizing and respecting the culture of the minorities and for failing to achieve a just redistribution of resources.

\section{Education Reforms and the New Imaginations of a National Citizenship}

The ties between education and social unrest and conflict in Sri Lanka are complex and are not yet fully accounted for and understood, but there is wide recognition that the link does exist. In the following section I discuss how this knowledge has been incorporated into new education policies. In 1989, a Presidential Commission on Youth was established with a mandate to examine the causes of youth unrest and provide recommendations. The report presented by the commission in 1990 was to slightly alter the focus of future educational policy making. The investigations suggested a causal link between the performance of the education system and the emer- 
gence of rebellious youths among both Sinhalese and Tamils. This turned conflict into an issue that the school system could no longer ignore, and one it was obliged to assist in solving. Influenced by this change in thinking, the National Education Commission that had been appointed in 1991 identified "the achievement of national cohesion, national integrity and national unity" and "establishment of pervasive patterns of social justice" as important national goals (Little 2003a). More initiatives were taken to reach the goal, among them the introduction of "peace education," but observers generally agree that the initiatives were largely unsuccessful (Ginige 2002; Matthews 1995:84; Perera et al. 2004:393, 410).

In 1997 the government introduced a new education reform, which it had engineered in consultation with international educational agencies and under influence of an emerging global agenda for education. ${ }^{3}$ New planning tools and management structures were introduced (Little 2003a), and new institutions were established to conduct policy-relevant research and advise the government. Perera et al. describe the reform as a milestone in the development of a national education policy that would address the country's major problems (2004:397), and that as the Ministry of Education phrases it, would be "enhancing life competencies and upholding the value of peace and social cohesion" (2005:6). Concrete changes include a new language policy, which prescribes that all children in government schools shall be taught the two national languages, Sinhalese and Tamil (Perera et al. 2004:402).

In addition, a comprehensive process has been launched to reorganize and improve the content of the most contested and controversial subjects (history, religion, and social studies), which are moreover to be systematically monitored for any ethnic, religious, gender, and poverty bias (Wickrema and Colenso 2003:11). Entirely new subjects that aim to "develop the total personality of the child" including the ability to build positive interpersonal relationships and accept diversity, have also been introduced (Perera et al. 2004:400; National Institute of Education 2006b).

One example is the subject of "citizenship education" for grades 6-9, which aims to create "citizens full of competencies and good virtues" who will "admire the culture multiplicity and develop competencies and positive attitudes towards national integration" (Educational Publications Department 2005:vii). The textbook for grade 7 illustrates the visions and values behind the subject. It is divided into three sections, which briefly deal with the individual's rights, duties, and obligations in the context of "the family," "our society," and "our culture," respectively. Sri Lanka's diversity is mainly addressed in the section on "our culture," where it is stated that "there are five races in Sri Lanka, namely Sinhala, Tamil, Muslim, Burgher, and Malay. They follow the religions Buddhism, Hinduism, Islam, Christianity and Catholicism" (Educational Publications Department 2005:30). This introduction is followed by brief descriptions of the major religious festivals of each community, which makes each group appear as having essentialized and separate cultures.

The text attempts to incorporate the different groups into a common imagined national community by stressing that all groups made significant contributions to the struggle for independence, that all are Sri Lankan citizens, and that Sri Lanka is their common motherland (Educational Publications Department 2005:29, 34). A separate section on human rights likewise intends to stress children's commonalities across ethnic divides and their inclusion in Sri Lanka as a democratic country where "all of us get the opportunity of enjoying several rights" according to the country's legal framework (Educational Publications Department 2005:26). These rights include "the 
right to criticize the ideas of other children and citizens," but not the "right to humiliate them or speak in a manner that will harass them" (Educational Publications Department 2005:28).

For grades 10 and 11, the newly introduced subject "civics and governance" creates the potential for an even more direct address of Sri Lanka's contemporary political predicaments. The 2007 syllabus for grade-10 students includes sessions on democracy, decentralization, and devolution; the multicultural society; economic systems and relations; and conflict resolution in a democratic society whereas grade- $11 \mathrm{stu}-$ dents study law and justice, government, human rights, environmental problems and sustainable development, and international relations (National Institute of Education 2006a, 2006b). The new reforms, in other words, outline a new social imaginary in which the prior national identity defined on the basis of Sinhalese cultural values is replaced with a multiethnic national identity that makes all citizens equal and that aims to inculcate a new culture of tolerance.

As the implementation of the new syllabus is still in its inception, it is premature to make any evaluation, but a few remarks of caution are in place. The reform relies heavily on curriculum change and on the written textbook as the agent of change in regard to reaching the particular objective of "national integration and unity" (Little 2003a; Perera et al. 2004). According to Wickrema and Colenso,

the textbook is very much the central component of the teaching-learning process, with teachers making little reference to the syllabus, to broader pedagogical resources, and to the development of broader competencies beyond the remit and content areas of textbooks. The historical monopoly of textbook production, combined with the reluctance of teachers and students to deviate from the textbook, has made the content of the single textbook that much more critical and contentious. [2003:3]

The prevalence given to the textbook can be linked to Sri Lanka's educational culture that stresses rote and exam-oriented learning, and the teacher is considered an authority figure whom you can ask questions, but not question (Perera 2006:22). As Stewick and Levinson suggest, however, new civic values of democracy and tolerance cannot be taught and internalized by students solely through abstract texts, but need to be firmly anchored in the social structure and practices of the school and this may pose one big challenge for the recent reforms (2007). Anthropological studies conceptualize education as an evolving social practice and the school as a vibrant and contested arena. The priorities outlined in educational policies, and concepts and values introduced in textbooks are significant aspects of the way in which children are "being made" as citizens, because they have authority. However, their real effect on children's self-perception can only be assessed by examining their implementation and appropriation in concrete social environments, where other actors introduce competing values and truths.

\section{The Negotiation of a Research Methodology}

The empirical data for this article stem from a field study that is part of a larger research project on education, conflict, and postconflict reconstruction in Sri Lanka. The field study took place during February and March 2006 in and around Puttalam town in the North Western Province, an area I am familiar with from earlier research and humanitarian work on war-related internal displacement and social reconstruc- 
tion. Puttalam town has always had a sizeable Muslim population, whereas the district's rural areas have been dominated by the Sinhalese. In October 1990, the LTTE expelled all Muslims from the north, and many ended up in temporary refugee camps close to Puttalam town or with resident relatives. The district's Muslim population thus went from 9.9 percent in 1981 to 18.8 percent of the population in 2001, and 67.5 percent of Puttalam town's 40,967 inhabitants are today Muslims (Department of Census and Statistics 2001). Population growth has generated fierce competition over scarce resources between the host and refugee populations (Hasbullah 2004; Sørensen 2001).

The field study involved five Tamil medium schools (grades 6-13), of which one is Roman Catholic, one Hindu, and three Muslim. ${ }^{4}$ I had planned to use participantobservation in classes and staff meetings in two schools as my main methodology to collect data on the everyday formation of citizenship in schools, but a number of incidents forced me to revise my research strategy and methodology. First, the local authorities were powerful "gatekeepers"; they demanded that I obtain their approval for each activity I wanted to carry out with teachers and pupils, which made more open-ended, participatory research incredibly difficult. Second, the crisis emanating from the publication of defamatory drawings of the Prophet Mohammed in a Danish newspaper had also reached Sri Lanka and made the Muslim community acutely alert to outsiders and their overt and possible covert agendas. Next, local elections were impending, and political meetings involving school staff frequently interrupted everyday routines in the schools. In some cases, this meant that research became a less urgent activity for my informants, whereas in others it contributed to exposing the sensitivity of the research topic. In consultation with educational officers and principals, I developed a research methodology consisting of questionnaires and focus group interviews with teachers and pupils, individual interviews with educational officers and principals, group interviews with representatives of school development societies and old pupils' associations, thematic workshops, photo and essay assignments with smaller groups of pupils, participation in public school events, and to a lesser extent casual conversations with pupils.

I also interviewed all NGOs in the area that had a child focus, and some of the major private tuition centers. In illustration of the sensitivity and significance of my research topic, activities with children in some cases took place under close supervision and direct interference of a gatekeeper appointed by the school or mosque, whereas in others the staff were engaged, helpful, and constructive facilitators of the research process. In my field diary I repeatedly noted that the research was far more complicated than any other research project I had carried out in Sri Lanka in terms of getting access to informants.

Because of my empirical research focus on the school, children were being categorized as schoolchildren and turned into subjects of the state to be surveilled and controlled, which is testimony of the extreme politicization of education in Sri Lanka. The change in methodology contributed to a slight change in research objectives from how citizenship is taught in class through the curriculum to how the school as an institution produces and conveys messages about citizenship through its organization and its position in the community (Bush and Saltarelli 2000:21). As the field research proceeded, this turned out to be a fortunate change in focus, which resonated well with the viewpoints and experiences expressed by most informants and that contributed 
with new insights about the interrelationship between aspects of recognition and redistribution that a focus on the content of textbooks alone could not bring forward.

\section{The Everyday Formation of Citizens}

Although the notion of citizenship is nearly universal, what it means and how it is experienced is not. The narratives of my interlocutors stressed two distinct but related dimensions of citizenship: access to resources and development, and cultural recognition and self-determination. These were expressed and defined in relation to my informants' vertical relationship with the nation-state and its representatives, and as part of their horizontal social relationships of solidarity (Kabeer 2005). My preparations for the field research had been informed by arguments in the scholarly literature and the public debate in Sri Lanka regarding the relationship between education and nation-building in conflict situations (Bush and Saltarelli 2000; Davis 2006). This had led me to expect that informants would talk excessively about the content of teaching material. The issue did occur, but in most cases concerns regarding the availability of resources were foregrounded, and I argue that the particular exposition and explanatory linking of issues contain instructive lessons regarding the conceptualization and experience of citizenship in Sri Lanka.

\section{Definition through Absence}

In each school, I asked pupils to produce a descriptive portrait of their school in text, drawings, or photos. Going through the presentations, I was struck by the fact that despite the evident differences in size and standard between the selected schools, the presentations were remarkably similar in both focus and content. With no exception and little variation they all concentrated on the defects and deficiencies of their schools, whereas more positive aspects were only given scant attention. Regardless of whether the school consisted of permanent, well-maintained brick buildings or it was located in a dilapidating and more humble construction, whether it had many or few teachers, well-equipped libraries and science laboratories or none at all, the students consistently tried to document the complete lack or insufficient availability and low standard of their school's facilities. ${ }^{5}$

When the children took me on a grand tour of their school, they guided me to overcrowded classrooms, sparsely furnished classrooms with little more than a ragged chair and desk for the teacher, and classrooms that were unusable because of leaky roofs and cracked floors. They showed me outdoor classes with small children sitting uncomfortably on the hot sand under a tree, following the soothing shade that demarcated the boundaries of their classroom, and they led me to shelters made from palm leaves (cadjan), which only gave the studying children minimal protection from the blazing sun and the torrential monsoon rains. The inadequate classrooms were not the only thing that concerned the pupils. In all the schools, pupils complained about libraries with empty shelves or outdated literature and poorly equipped science labs. Moreover, the pupils were troubled by the poor standard of sanitation that constituted a serious health hazard and contradicted all they had learned about good health. 
Their photo essays illustrated the prevailing situation with countless photos of garbage piled up in the school ground; wells where the water surface was covered with plastic shopping bags, paper and other rubbish; and stinking filthy latrines. Complaints over the lack of a school fence, which gave easy access for stray animals and other trespassers, were also frequent. The children's perception was widely shared among the staff and management, who matched the pupils' documentation of absence with detailed, meticulously prepared lists of what was needed, in what numbers and amounts.

Experiences of neglect were not only expressed in relation to infrastructure and facilities. On more occasions, principals and teachers complained that their school did not receive the regular visits from the educational office where deficiencies would be recorded and useful professional support provided. Although the staff was obviously not interested in excessive interference of external authorities, the infrequent visits of officials prevented communication and were interpreted not only as misconduct but also a strong indicator of the school's and the whole community's low public status. In a similar vein, I was informed of several incidents, where no action was taken by the authorities when the school management reported criminal acts such as illegal encroachment or theft of computers and other valuables from the school.

To see how these identifications and expositions of missing or deplorable facilities and absent or nonattentive authorities relate to the formation of situated notions of citizenship, it is necessary to explore how pupils and staff themselves interpreted and explained their situation. The children's reflections regarding the standard of their school are interesting as they imply an objectifying, comparative gaze. The children's negative evaluation of their school made implicit reference to an idealized cultural image of how a school ought to be, and explicit reference to Sinhalese majority schools and to national schools that receive direct funding from the government. Both were perceived to have a surplus of resources and to be closer to the ideal. In several cases, however, the schools of neighboring villages belonging to the same ethnic community, were also perceived to be better off. In both cases, differences in access to resources were typically explained to be the direct result of politics.

As scholars examining the development of the modern Sri Lankan state have pointed out, the introduction of a representative form of government and universal suffrage in 1931 resulted in growing attention to the needs and grievances of their constituencies, and even before independence, the provision of welfare had become a central-and costly - feature of the Sri Lankan state (Brow 1996; Hettige 2004; Jayaweera 2007; Richardson 2004). As I have argued elsewhere (Sørensen 2008), the authority and legitimacy of the Sri Lankan state is today highly dependent on its provision of welfare to its citizens, and the population claims a principled right to development. Apart from contributing to material and social welfare, the provision of resources also serves as a symbolic recognition of the receiving group's inclusion in the national community as citizens. Conversely, the lack of development can be regarded as testimony of a group's exclusion or marginalization from the national community. The relative absence of the state in the minority schools symbolized in the lack of classrooms, the absent or broken furniture, and the shortage of teachers is, as I see it, as powerful a communication about the nature of the Sri Lankan nation-state as is its presence through flags, anthems, and textbooks, which is typically in focus in studies of education and nation-building. When my informants showed me the 
missing facilities, they were evoking not only an image of the archetypical Sri Lankan school but also their social imaginary of the state.

My informants' accounts of absence, I argue, serve an argument of state-based discrimination against minorities, not unlike that inherent in analyses of how the nation-state imposes itself symbolically through textbooks or social ceremonies. But whereas the state's strong symbolic presence provokes alienation, resistance, or at least distance, focus on its relative absence appears instead to function as a tactic for claiming a position as rightful Sri Lankan citizens and an attempt to compel the state to recognize its moral obligation to deliver welfare and take proper care of all its citizens. The teachers and pupils, in other words, practiced what Jackson calls a "politics of storytelling" (2002) when they voiced what in their view were legitimate expectations toward the government and politicians to provide appropriate facilities for learning.

Their expectations were repeatedly echoed in my conversations with parents and teachers. As one principal expressed it, "Of course we would like to get the assistance from the government. But we do not get [it], so we approach other possible sources of funding. But even when the assistance of NGOs is considerable, they can only help with buildings and our material needs. The real problem here is teaching and the lack of teachers, and only the government can—and should—solve that" (interview, 6 March 2006). I suggest then that what at first appeared simply to be depressing accounts of schools in a deplorable state could also be interpreted as unassuming, but insistent claims for recognition and inclusion in the political and moral national community as citizens with equal rights and opportunities. The social imaginary of equal citizenship contained in the previously discussed textbook for citizenship education in other words finds resonance among teachers and children, but contrary to what the textbook explains, they know that inclusion has to be continuously worked for, at least when you do not belong to the Sinhalese majority or enjoy the benevolence of a powerful patron. In the following, I explore further how staff and pupils perceived the logics of politics to work, and how that formed their experience of citizenship.

\section{Multiple Orders of Marginalization}

Citizenship refers to both rights and entitlements, and to a sense of identity and belonging (Fraser 2003; Kabeer 2005; Ong 1996). Although pupils in all schools and of all ages expressed their grievances over the poor physical conditions at their school in similar ways and agreed that the main reason was political, significant patterns of difference emerged, when I explored the existing explanations of this inequality.

In the Hindu school, the older pupils, who were entering a more demanding and decisive phase of their education, were particularly outspoken on the issue. From their perspective, the most grave problem was the acute shortage of qualified teachers and the lack of good learning materials, as this directly affected their education, exam results, future career opportunities, and social positioning. As mentioned earlier, the large number of vacancies in Tamil-speaking schools has for several years been a hot issue repeatedly brought up by Tamil politicians and educationalists. Although the authorities seek to explain away this problem by referring to the warlike situation prevailing in large parts of the Tamil region, my student informants did not hesitate to diagnose it a result of discrimination, which evidenced that they were not fully recognized as a minority. 
For the students the shortage of teachers had dire consequences, as they missed out on important classes, which reduced their chances of passing exams. Many families tried hard to raise money to send their child to private tuition classes, but it was costly and could be risky too, as this account by an A-level male student reveals, "You see, in our school we don't have any math teachers for A-level, so I have to travel to Colombo once a week to take extra classes. I want to go to university." After a pause he continued, "but I'm scared to travel, because if something happens, it can be dangerous to be a young Tamil boy, especially if you come from Jaffna" (interview, February 16, 2006). In a workshop with this young student and his classmates, the discussion fell on learning material. "Very often our textbooks are several months late, and that makes it difficult for us to cover the curriculum in time to prepare for exams," one boy informed. A classmate took over, explaining that this delay was partly because of the fact that most textbooks are first written in Sinhalese and then translated into Tamil and distributed to Tamil-medium schools.

Moreover, the translations are frequently of poor quality, as exemplified by another student. "We find it very difficult to read the texts and understand the questions [for exams], so we spend too much time understanding them and then we have less time to answer them." And his conclusion, uttered with a mixture of disdain and self-pity, was disturbing: "This is done to make us Tamils look more stupid than the Sinhalese!" To support their friend's conclusion, others quickly added that education programs on TV were also only targeting Sinhalese students, again reducing the opportunities for Tamil students to do well in the competition for access to higher education and good jobs (workshop, February 16, 2006).

Echoing the elder students' concern and their allegations of state-sponsored discrimination against them as a minority, the management and senior staff revealed their utmost frustration that official meetings and written documents and letters from the authorities were most often in Sinhalese, a language in which most lacked proficiency. After having explained how translations of circulars, regulations, letters, and other documents occupied much of his own and the secretariat's time, and how humiliated he felt at meetings when having to explain his situation in a language that was not his mother tongue, the principal of one school stated, "It makes me feel like a second-rank citizen in my own country" (interview, February 16, 2006). Although such comments undoubtedly emerged from lived experiences, they were clearly also embedded in and nourished by the collective narrative of the Tamil minority's grievances and struggles for cultural recognition and self-determination.

The Muslim schools of the study included two newer schools that mainly catered for the children of displaced families, and one older school in an impoverished neighborhood in the town periphery. Unlike the Tamil informants, the Muslim teachers and pupils here did not evoke their religious identity or minority position as explanatory factors per se when commenting on their educational situation. But how then did the Muslim teachers and pupils explain what they nevertheless perceived to be acts of discriminate distribution within the educational field?

In the two schools for children of internally displaced parents, strong emphasis was being put on the traumatic and disruptive experience of displacement, which had entered social memory and become part of the community's social identity. One group of pupils concluded their written account of the difficulties they faced in school, with the following words. "Displacement is the reason for that. Our property, education rights, everything was destroyed when we were displaced from our native 
place in the Vanni by weapon-holding Tigers." The narratives of displacement called to mind memories of the prosperous and successful schools that had been left behind and stressed that education had turned into a struggle hard to win, because resources were fewer and competition greater. Inclusion in the humanitarian category of internal refugees, however, not only signaled a separation from territory, property, and possessions but also spelled a restriction in the internally displaced people's ability to participate in politics. This was important because the majority of schools and other social services are funded by the provincial government, and gaining access to funds in many cases was dependent on being able to build effective patron-client relationships.

The displaced Muslim population remained registered in the province they had been forced to flee, and hence could not cast their votes for politicians in the province of their residence and in this way turn their concerns into publicly recognized political priorities. At the same time, there was little chance that votes for the politicians in their home province would have any effect either, as they were unlikely to be willing to transfer resources to another district (Hasbullah 2004). As one informant phrased it, "Votes, not needs, determine what you get," and he thereby stressed that ordinary politics had replaced humanitarian practice, and that because of their unresolved situation of prolonged displacement, the Muslim community was prohibited from participating in both the humanitarian and the political game. The experience of lack of political rights was accentuated by the daily experience of stigmatization by the host community, which made them feel out of place as evidenced by this extract from an essay written by a young boy: "I suffer like a person sunk in floods... I will wait for the day that erases the label of refugee."

The third Muslim school, established in 1971, was situated in a poor neighborhood. Most families depended on low-paid casual labor in local salt pans and fisheries, and the community suffered from a wide range of poverty-related social problems such as alcoholism, drug abuse, crime, fighting, malnutrition, illiteracy, and health problems. Education was also affected with long-term absenteeism and a high dropout rate, lack of support from parents, and irregular presence of teaching staff. According to the School Development Society (SDS), they had approached many politicians and NGOs for support and assistance, but had in most cases been disappointed. Some politicians had made visits and delivered speeches that promised to improve the school and bring development, only to neglect the community afterward. According to the SDS, the community was neglected because it did not support the government, and because the community was considered backward, rude, hostile, and of little prestige. This reflected on the image of school, which was publicly referred to as a "punishment station," which only principals of the "wrong" political observation or with a blemished record would be appointed to and that teachers would do their best to escape. The NGOs did not provide an alternative solution, because they mainly focused on children of displaced families, and there were only a small number of displaced families in the community. The pupils of this school did not point to a single factor (ethnicity), or a single event (displacement) as the cause for their misfortune, but instead conceived of themselves as belonging to an impoverished and hard-pressured group, who had to battle exploitation and exclusion on several fronts, including from within, and whose identity had largely been conflated with its socioeconomic position. 
The Roman Catholic school had been established under colonial rule, but later been moved to a new locality outside town. Its present principal was Roman Catholic, but its teachers and pupils included many Muslims and Hindus from the area. The community it supported was poor, largely dependent on low-paid seasonal work and lived dispersed on different small islands and coastal villages. The accounts of the pupils of this school were less concerned with finding an explanation for the lack of facilities and more focused on past achievements and future challenges. This may be because of their younger age, them coming from more remote areas, or the strong discipline and compassionate atmosphere that prevailed at the school. Whenever they voiced some critical reflections these were more often directed at themselves and their own community, and concerned problems related to labor migration, the difficult position of girls, or the temptations of consumerism.

The principal and teachers, however, soon introduced the topic of politics in our discussion about the school. Being a small Tamil-medium school, they generally felt less privileged, and time and again they had experienced how their arguments and requests for support fell on deaf ears, whereas the neighboring Sinhalese school received excessive support from the authorities. Moreover, the principal had experienced how her family's close connections to the political opposition had been used against her. Contrary to the other schools, however, such experiences did not appear to have mobilized a strong collective narrative of blame, nor had it generated a claim for cultural citizenship. Instead, the situation seemed to have given rise to a strong sense of communal solidarity and united them in a dedicated struggle to slowly, but surely improve the children's and the community's socioeconomic situation through an education based on respect, tolerance, and discipline.

The experiences of the different schools in this section remind us to be apprehensive of how the formation of citizenship as a political process may employ numerous and shifting categories of differentiation, intertwining aspects of redistribution and recognition. In this section I have exemplified how authorities through their interventions in education contributed to defining and positioning teachers, pupils, and their families as citizens. Despite the official policy that all are equal citizens, none of my informants expressed a sense of full recognition and inclusion, and in the next section I analyze in more detail how their experience of "partial citizenship" affects their acts of "self-making."

\section{The Creation of Peripheral Citizenship}

The perception of deprivation and of partial citizenship that existed in schools resulted neither in apathy nor in actual resistance, but, rather, in innumerable activities to reduce its negative effects. As I shall show, these activities were insistent acts of self-making (Ong 1996) that creatively exploited possibilities in the prevailing system to regain a sense of pride and control and define meaningful forms of membership and belonging.

At the time of my fieldwork, political campaigns and meetings preceding local elections were frequent. Although there was little confidence in politics among my informants, most principals and senior teachers would nevertheless partake in meetings organized by the authorities and contesting parties with the vain hope that they would receive gifts for the school or succeed in forcing promises of future assistance. And even when they did not receive anything at most meetings, not being present 
could easily be interpreted as offensive and strain relationships. The schools, however, developed several alternative strategies to improve their situation, and these were expressive of and contributory to forming their citizenship from below. The strategies from below concentrated on mobilizing social networks of different kinds, and contrary to the political relationships that were framed by the logic of resources in return for votes or other kinds of reciprocal exchange, these networks, I argue, rested on moral notions of commonality and expressed citizenship as horizontal solidarity (Kabeer 2005).

The kinds of social networks that different schools were capable of mobilizing to buttress support varied a great deal, as did their resources and capacities. All schools in Sri Lanka have a School Development Society (SDS) with teacher, parent, and pupil representatives. Their task is to facilitate the relationship between a school and the community and to assist the school in solving emerging problems, and they were typically a strategic player in addressing lack of resources. For instance, they would initiate social activities in the community to generate money to pay voluntary teachers or smaller infrastructure projects. In one of the schools, situated in a community of displaced Muslim families, the SDS had been more ambitious and rented a van to go on a grand fund-raising tour from their village to Colombo to raise money for the replacement of a temporary shelter with a permanent brick building. Their main targets were the many successful Muslim businessmen who had established their enterprises along the main road and who, according to the SDS, had a moral obligation to support their community. Another target was a Muslim politician who had succeeded in becoming a national minister, and whose family shared the experience of displacement. Even though his ministry's mandate did not directly match the school's concerns, there was wide agreement that he too had a special obligation to support his community, which he did on several occasions. So although the Muslims generally complained over their lack of political representation in the area, they were not without initiative and repeatedly demonstrated that their extended social networks possessed considerable resources and willingness to step forward in support of the community.

Students at the Hindu school expressed a similar doubt about the support of politicians. One group of students wrote in their essay: "There will be so many politicians coming and going. They will say so many things and create so many ideas in our minds, but they don't fullfill even 1 percent." And therefore they too had to rely on their own resources. The Hindu school's social network reflected the Tamils' traditional pursuit of careers as lawyers, engineers, doctors, and university professors. The most important network was the old boys' association (OBA) that counted more than three hundred members in Sri Lanka and abroad.

Over the years, the OBA had repeatedly demonstrated its indisputable loyalty when it had helped raise money for land purchase, a proper school gate, the construction of a Hindu shrine, and a science laboratory. Members also helped to improve teaching at the school by volunteering to give lectures of interest and relevance to the pupils. The worth of the OBA was widely acknowledged, and the students did not hesitate to ascribe the success of their school to the commitment and loyalty of former students. A group of students wrote, "The present situation of this school is achieved by the Old Boys' Association. They have helped the school a lot," and the students anticipated that they too would remain supportive of their school. "We will do as much as we can for our younger brothers and sisters." 
Contrary to what could be expected from a policy that promises free education, a substantial part of the schools' activities and investments were in fact covered by the schools themselves and their social networks. This meant that the two schools that served poorer and largely illiterate communities were in fact doubly marginalized, because they did not have a resourceful network to mobilize. The main point I want to draw from these examples, however, is that the work of the SDSs and OBAs has a significance that goes well beyond its economic aspects, in that it contributes to shaping the children's sense of who they are. Every time the SDS or the OBA contributed something to the school, it was interpreted and praised as "our own achievement" as opposed to something allocated by the state or some other external agent. Hence the achievements of the SDS and the OBA served to reinforce identification with and pride in the school and the local community. Appadurai's (1998) distinction between "neighborhood," which refers to situated communities, and "locality," which is a property of social life, are useful here (1998). According to Appadurai, neighborhoods exist in opposition to the nation-state's social imaginary of a homogenous population, and constitute a "a perennial source of entropy and slippage" (1998:191), because they are concerned with their own reproduction, for which they depend on the production of "local subjects" (1998:179). The pupils" tribute to the SDSs and OBAs was clear evidence of the schools' attempts and success in producing loyal local subjects, and so was the pupils' unequivocal view that the purpose of their education was to enable them to "do good for the community."

Ironically, the segregated national school system can be argued to support this process that entails a real or potential contestation of the nation. Contrary to the argument regarding the national socialization of pupils through the invasion of the school space with national symbols, I found that the symbolic space and daily routines of the schools were far more expressive of the community's own religious and cultural values than of their incorporation into a national space. The Muslim schools all had a small mosque or prayer room for staff and pupils, and the school flags, emblems, mottos, and school anthems all established unambiguous links between Islamic virtues and education. Offices and classrooms were decorated with posters from Mecca or quotes from the Quran, and the community's cultural identity was inscribed on bodies through a particular dress code and temporal structuring of the day.

At the Hindu school a statue of the goddess of speech, wisdom, and learning, Saraswathy, welcomed teachers, students, and other visitors at the gate, and just inside was a Hindu shrine, which to the principal's regret still needed some work before it could be used for religious functions at the school and become a natural rallying point for the Hindu community. The school secretariat was decorated with posters of Hindu gods and goddesses, ceremonial oil lamps, and other religious and cultural paraphernalia. And the walls in the library were decorated with framed pictures of Indian notabilities such as Jawaharlal Nehru, Indira Ghandi, and classic Indian writers and thinkers that accentuated the importance of language and traditional arts and culture and the Indian roots of Tamil culture. The particular configuration of the social spaces of the Muslim and Hindu schools, I argue, effectively challenged the nation-state's attempt to impose its own order on the schools. According to Fernandez there exists "a mode of knowledge on the periphery, which is to invert the boundary relationship; to conceptualize itself as central and the putative center as remote, inept, peripheral to its own essential values" (2000:12). In all the schools politics was perceived to have a major impact on education, and that instead 
of producing equal citizenship it resulted in inequality and misrecognition. The schools that appeared most successful in countering this labeling and its ramifications were those that managed to "invert the boundary relationship," to use Fernandez's expression (2000:12) and to make a center of itself, or to produce what could be termed peripheral citizenship, where both recognition and redistribution to a large extent stemmed from internal sources and solidarity.

\section{Changing Policies or Politics?}

In recognition of the fact that education plays a significant role in the socialization of pupils as citizens and that education in conflict and postconflict situations has become a site of intervention of growing importance, I shall conclude by briefly reflecting on the policy relevance of my analysis. Like many other governments, the Government of Sri Lanka has decided to combat conflicts and foster social cohesion through education. A key strategy has been to eliminate discriminatory contents from learning material and to develop a new curriculum including subjects related to peace, tolerance, and citizenship. Leaving aside the many difficulties pertaining to effective implementation of the strategy, the question remains as to whether it is likely that an improved curriculum will deliver a significant change in attitudes and behavior and hence to contribute to peace and social cohesion. As my analysis suggests, there are several reasons why this is indeed doubtful.

Even though many of my informants at some point mentioned the need to better accommodate the histories, values, and viewpoints of different communities in school textbooks, they were generally far more concerned with the uneven access to quality education. The appointment of principals and teachers, the allocation of resources for buildings, equipment and facilities, the distribution of books, and the engagement of relevant authorities were repeatedly brought up as examples that contradicted the notion of equal citizenship that was contained in textbooks, and replaced them with a sense of partial citizenship. The main reason for this was to be found outside the school and classrooms, in the extreme influence of politics on education. The decentralization of government and resources in Sri Lanka has generated a political structure based on patron-client relationships, where recognition and resources are exchanged for votes or other favors. As shown in the discussion political patronage first of all operates on the basis of ethnic distinctions, which put the Sinhalese majority at the apex and opposes it to the ethnic minorities. However, other distinctions such as occupation, legal status, and political affiliation are also frequently put to work and created their particular experiences of inclusion and exclusion, and as argued they also paved the way for constructions of an alternative local, peripheral citizenship.

Reflecting on the limitations of the curriculum as an agent of change in conflict situations, Bekerman asserts that "only that which is done is learned . . . only that which is done through sustained effort and is able to echo in multiple contextual social settings stands a chance to enter memory and be acted upon so as to become part of the social fabric" (2005:240). My analysis similarly suggests that more attention must be paid to children's total experience of going to school, and these are structured by the wider society in general and the political system and political culture in particular. In other words, it is the political system-its manner of distributing resources and hope, its way of generating material and mental categories of differentiation-that needs to undergo change. As long as children experience deprivation and discrimination and 
see these as the result of a system where "politics and not policies count" as one informant phrased it, then they are unlikely to induce the notion of equal Sri Lankan citizenship with any credibility and will instead turn to ethnic and other local notions of citizenship that can guarantee them some degree of security.

Birgitte Refslund Sørensen is associate professor at the Department of Anthropology, Copenhagen University. She has carried out extensive research on Sri Lanka, including issues such as development-induced displacement and resettlement, community and capacity building, postconflict social reconstruction, and humanitarian assistance (birgitte.soerensen@ anthro.ku.dk).

\section{Notes}

Acknowledgments. I wish to thank all the administrators, principals, staff, and pupils, who welcomed me into their worlds and so generously shared their experiences and thoughts with me. Mrs. Subadra Hudson deserves special thanks for assisting me in the field and for spending endless hours translating field data.

1. Sri Lanka was known as Ceylon until 1972, but for the sake of simplicity I use its current name for all historical periods.

2. Tamil Eelam is the name of the independent state to which the LTTE aspire.

3. Although interesting, it is beyond the scope of this article to discuss the influence of globalization and international aid on Sri Lanka's education system.

4. Sri Lanka's schools are segregated according to medium of instruction. 68 percent of the schools are Sinhala-medium, 29 percent Tamil-medium, 0.5 percent Sinhala and Tamil 45, 1.8 percent Sinhala and English, 0.5 percent Tamil and English, whereas 0.2 percent teach in Sinhala, Tamil, and English. The corresponding figures for Puttalam's 343 schools are: Sinhalese-medium (78 percent), Tamil-medium (20 percent), Sinhala- and Tamil-medium (1 percent), and Sinhala- and English-medium schools (1 percent; see Ministry of Human Resource Development, Education and Cultural Affairs 2004). Schools are moreover categorized according to religion and there are Buddhist, Hindu, Muslim, Roman Catholic, and Christian schools (Perera et al. 2004:396).

5. I want to stress that my research does not disclose whether or to what extent my informants' views were substantiated by hard facts, but as Richardson argues, "in an ethnically conflicted society ... it is perceptions of relative deprivation rather than abstractions crafted by economists that matter" (2004:60).

\section{References Cited}

Appadurai, Arjun

1998 [1996] The Production of Locality. In Modernity at Large: Cultural Dimensions of Globalization. Pp. 178-199. Minneapolis: University of Minnesota Press.

Bekerman, Zwi

2005 Are There Children to Educate for Peace in Conflict-Ridden Areas? A Critical Essay on Peace and Coexistence Education. Intercultural Education 16(3):235-245.

Brow, James

1996 Demons and Development: The Struggle for Community in a Sri Lankan Village. Tucson: University of Arizona Press.

Bush, Kenneth, and D. Saltarelli

2000 The Two Faces of Education in Ethnic Conflict: Towards a Peacebuilding Education for Children. Florence: UNICEF Innocenti Research Centre.

Davis, Lynn

2006 Education for Positive Conflict and Interruptive Democracy. In Education, Globalization and Social Change. Hugh Lauder, Phillip Brown, Jo-Anne Dillabough, and A. H. Halsey, eds. Pp. 1029-1037. Oxford: Oxford University Press. 
Department of Census and Statistics

2001 Census on Population and Housing. Electronic document, http://www.statistics. gov.lk/PopHouSat/PDF/Population/p9p8\%20Ethnicity.pdf, accessed August 10, 2008.

Educational Publications Department

2005 Citizenship Education: Grade 7. Battaramulla: Educational Publication Department.

Fernandez, James

2000 Peripheral Wisdom. In Signifying Identities. Anthropological Perspectives on Boundaries and Contested Values. Anthony Cohen, eds. Pp. 117-144. London: Routledge.

Fraser, Nancy

2003 Social Justice in the Age of Identity Politics: Redistribution, Recognition, and Participation. In Redistribution or Recognition? Nancy Fraser and Alex Honneth, eds. Pp. 7-109. London: Verso.

Ginige, Indira Lilamani

2002 Education Research for Policy and Practice: Secondary Education Reforms in Sri Lanka. Educational Research for Policy and Practice 1:65-77.

Gunaratna, Rohan

1990 Sri Lanka: A Lost Revolution? The Inside Story of the JVP. Kandy: Institute of Fundamental Studies.

Hasbullah, S. H.

2004 Justice for the Dispossessed: The Case of a Forgotten Minority in Sri Lanka's Ethnic Conflict. In Sri Lankan Society in an Era of Globalization: Struggling to Create a New Social Order. S. H. Hasbullah and Barrie M. Morrison, eds. Pp. 221-240. New Delhi: Sage.

Hettige, Siri T.

2004 Economic Policy, Changing Opportunities for Youth, and the Ethnic Conflict in Sri Lanka. In Economy, Culture, and Civil War in Sri Lanka. Deborah Winslow and Michael D. Woost, eds. Pp. 115-130. Bloomington: Indiana University Press.

Jackson, Michael

2002 The Politics of Storytelling. Violence, Transgression and Intersubjectivity. Copenhagen: Museum Tusculanum Press.

Jayaweera, Swarna

2007 Schooling in Sri Lanka. In Going to School in South Asia. Amita Gupta, ed. Pp. 167-194. Westport, CT: Greenwood.

Jeffery, Patricia

2005 Introduction: Hearts, Minds and Pockets. In Educational Regimes in Contemporary India. Radhika Chopra and P. Jeffery, eds. Pp. 13-38. New Delhi: Sage.

Kabeer, Naila, ed.

2005 Inclusive Citizenship. Meanings and Expressions. London: Zed.

Liberation Tigers of Tamil Eelam (LTTE)

2006 Caring for the Children in Tamileelam. Press Release. Released on the Children's Day on 1 October 2006 by Child Protection Authority, LTTE Peace Secretariat. Electronic document, http:/ / www.ltteps.org/?view=1622andfolder=2, accessed November 6, 2006.

Little, Angela

2003a Education for All: Policy and Planning Lessons from Sri Lanka. Sevenoaks: DFID Education Publications.

2003b Labouring to Learn: Towards a Political Economy of Plantations: People and Education in Sri Lanka. Colombo: Social Scientists' Association.

Matthews, Bruce

1995 University Education in Sri Lanka in Context: Consequences of Deteriorating Standards. Pacific Affairs 68(1):77-94.

Ministry of Education

2005 Education for Economic Development and Prosperity. Battaramulla: Ministry of Education.

Ministry of Human Resource Development, Education and Cultural Affairs

2004 School Census-2003. Preliminary Report. Battaramulla: Ministry of Education.

National Institute of Education

2006a Civics and Governance: Syllabus Grades 10 and 11. Maharagama: National Institute of Education. 
2006b Life Competencies and Civic Education: Syllabus Grade 6. Maharagama: National Institute of Education.

Nissan, Elizabeth

1996 Sri Lanka: A Bitter Harvest. London: Minority Rights Group.

Ong, Aihwa

1996 Cultural Citizenship as Subject-Making. Immigrants Negotiate Racial and Cultural Boundaries in the United States. Current Anthropology 37(5):737-762.

O'Sullivan, Meghan

1999 Conflict as a Catalyst: The Changing Politics of the Sri Lankan Muslims. In Conflict and Community in Contemporary Sri Lanka. "Pearl of the East" or the "Island of Tears"? Siri Gamage and I. B. Watson, eds. Pp. 253-278. Colombo: Vijitha Yapa Bookshop.

Perera, Lal, S. Wijetunge, and A. S. Balasooriya

2004 Education Reform and Political Violence in Sri Lanka. In Education, Conflict and Social Cohesion. Sobhi Tawil and Alexandra Harley, eds. Pp. 375-433. Paris: UNESCO, International Bureau of Education.

Perera, Sasanka

2006 Sri Lankan Education System as a Reflection of Society's Ruptures: A Conceptual and Theoretical Exploration (draft). Electronic document, http://www.education.gov.lk/ nec/documents/nec_rs_007.pdf, accessed July 20, 2006.

Ponnambalam, Satchi

1983 Sri Lanka. The National Question and the Tamil Liberation Struggle. London: Zed.

Richardson, John M., Jr.

2004 Violent Conflict and the First Half Decade of Open Economy Policies in Sri Lanka: A Revisionist View. In Economy, Culture, and Civil War in Sri Lanka. Deborah Winslow and Michael D. Woost, eds. Pp. 41-72. Bloomington: Indiana University Press.

Rosaldo, Renato

1994 Cultural Citizenship in San Jose, California. PoLAR 17(2):57-63.

Sambandan, V. S.

2004 History from the LTTE. Frontline 21(3), January 31-February 13. Electronic document, http://www.flonnet.com/fl2103/stories/20040213000206000.htm, accessed August 2007.

Selvarajah, M.

2003 Education in the Conflict Areas in Sri Lanka: A Case for Capacity Building at Local Schools in Batticaloa. In Building Local Capacities for Peace. Rethinking Conflict and Development in Sri Lanka. Markus Mayer, D. Rajasinghan-Senanayake, and Y. Thangarajah, eds. Pp. 288-304. New Delhi: MacMillan.

Smith, A., and T. Vaux

2003 Education, Conflict and International Development. DFID Issues Paper. London: DFID.

Sørensen, Birgitte Refslund

2001 Sri Lanka: Developing New Livelihoods in the Shadow of War: Displaced, Relocated and Resettled Muslims. In Caught between Borders. Birgitte Refslund Sørensen and Marc Vincent, eds. Pp. 172-202. London: Pluto.

2008 Humanitarian NGOs and Mediations of Political Order in Sri Lanka. Critical Asian Studies 40(3):89-113.

Stewick, E. D., and B. Levinson, eds.

2007 Reimagining Civic Education. How Diverse Societies Form Democratic Citizens. Plymouth: Rowman and Littlefield.

Stokke, Kristian

2006 Building the Tamil Eelam State: Emerging State Institutions and Forms of Governance in LTTE-controlled Areas in Sri Lanka. Third World Quarterly 27(6):1021-1040.

Wickrema, Ariya, and Peter Colenso

2003 Respect for Diversity in Educational Publication-The Sri Lankan Experience. Electronic document, http:/ / siteresources.worldbank.org/EDUCATION/Resources/ 278200-1121703274255/1439264-1126807073059/Paper_Final.pdf, accessed May 14, 2007. 